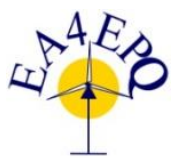

INTERNATIONAL CONFERENCE ON RENEWABLE ENERGIES AND POWER QUALITY (ICREPQ'18)

Salamanca (Spain), $21^{\text {th }}$ to $23^{\text {th }}$ March, 2018

Renewable Energy and Q Ower Quality Yournal (RE\&PQJ)

ISSN 2172-038 X, No.16 April 2018

\title{
Comparative Analysis of the 6/4 and 8/6 Switched Reluctance Generator in Different Operating Conditions
}

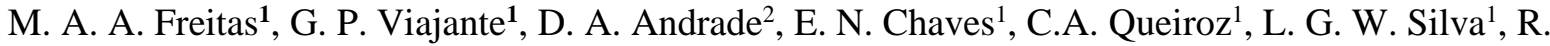 \\ V. R. Silva ${ }^{1}$, R.T. Fidelis ${ }^{2}$ and J.L. Domingos ${ }^{1}$ \\ ${ }^{1}$ Federal Institute of Education, Science and Technology of Goiás. \\ Energy Systems Research Center (Núcleo de Pesquisas em Sistemas de Energia - NuPSE) \\ Phone/Fax number: 5564 343152005, e-mail A: marcos.freitas@ifg.edu.br \\ ${ }^{2}$ Electric Drives Laboratory, Federal University of Uberlândia \\ Campus Santa Mônica, Uberlândia-MG, Brasil. \\ Phone/Fax number: 5534 3239-4411, e-mail: B. darizon@ufu.br
}

\begin{abstract}
This paper presents a comparative study between two Switched Reluctance Generators 6/4 and 8/6 both of $60 \mathrm{~kW}$. The main features of the two machines and the mathematical modeling that considers the magnetic saturation effect are established. A computational simulation was performed in Matlab/Simulink environment and has allowed the machine behavior under various operating conditions to be verified. This work made it possible to evaluate: ripple voltage, phase voltage and current, speed, torque, flux, power, losses and efficiency. The comparative results between the two generators are presented and discussed.
\end{abstract}

\section{Keywords}

Switched Reluctance Generator, Half Bridge Converter

\section{Introduction}

The increasing energy demand requires process optimization, cheaper products with less impact on the environment in addition to the search for new ways to use renewable energy such as solar, wind, biogas, etc. This has increasingly provided the development of innovative technologies applied to these systems. In this context, several researches have been carried out in search of other alternatives to using special electric machines in the harnessing of wind energy.

One of these alternatives that has stood out is the Switched Reluctance Generator (SRG).
The rising attention given to the SRG in the last two decades is due to its characteristics such as assembling simplicity, robustness, toleration to lack of phase, low manufacturing cost, high temperature endurance, variable speed operation, etc.

These features added to the performance in a wide range of operating speed variation, including extremely high speeds, led to the development of researches in order to improve the machine design to be used as a generator and establish control strategies aiming to optimize the generation [1][2][5] and/or make it applicable in wind energy systems.

In the production scale of wind energy the use of synchronous and asynchronous machines has traditionally been chosen through the use of synchronous generators and induction generators.

However the SRGs have been emerging and revealing to be a quite viable alternative having become the object of several researches that proposes to investigate the behavior of these machines operating as generators.

The literature is abundant in the design, modeling and simulation of Switched reluctance machines (SRMs) operating both as a motor and as generator [5][6][8]. Most of these works focus their analysis on three-phase generators/motors with 6 poles in the stator and 4 poles in the rotor $(6 / 4)$.

Other authors also suggest the use of the fourphase SRM with 8 poles in the stator and six poles in the rotor $(8 / 6)$. The fact is that the two configurations of SRMs (6/4 and 8/6) are the most popular in literature and that is why this work proposes to compare them. 


\section{Design Aspects of the SRMs}

Regarding the design aspects the SRMs have as main feature the presence of salient poles both in the rotor and the stator as shown in Figure 1.

In its traditional arrangement the coils pairs located at diametrically opposite poles constitute a phase of the machine. Thus, for a SRM, A1 and A2 form the phase $a, \mathrm{~B} 1$ and $\mathrm{B} 2$ phase $b, \mathrm{C} 1$ and $\mathrm{C} 2$ phase $c$ and D1 and D2 form phase $d$.
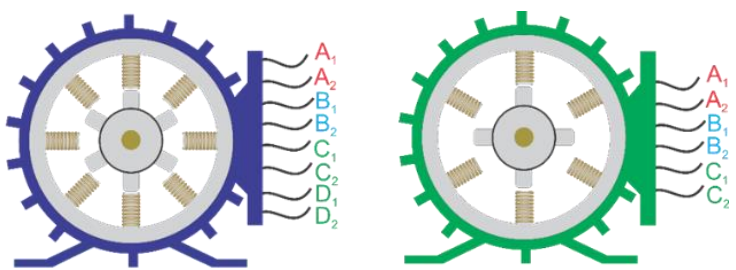

Fig. 1. View of SRG's $8 / 6$ and $6 / 4$.

The rotor is made of ferromagnetic material has no windings and is usually assembled to work with low inertia. Table 1 shows the data of the $6 / 4$ and $8 / 6$ machines used in this work.

Table 1. Parameters of SRG (6/4) and (8/6).

\begin{tabular}{l|l}
\multicolumn{1}{c|}{ Parameters } & \multicolumn{1}{c}{ Values } \\
\hline Number of poles (stator and rotor) & $6 / 4 \mathrm{e} 8 / 6$ \\
\hline Output power & $60 \mathrm{~kW}$ \\
\hline Stator resistance & $0,01 \Omega$ \\
\hline Moment of inertia & $0.0082 \mathrm{Kgm}^{2}$ \\
\hline Viscous friction & $0,01 \mathrm{Nm}$ \\
\hline Inductance in alignment & $23,6 \mathrm{e}-3$ \\
\hline Inductance in misalignment & $0,67 \mathrm{e}-3$
\end{tabular}

Figure 2 shows the typical curves for inductance, phase current, and trigger pulses of the SRGs.

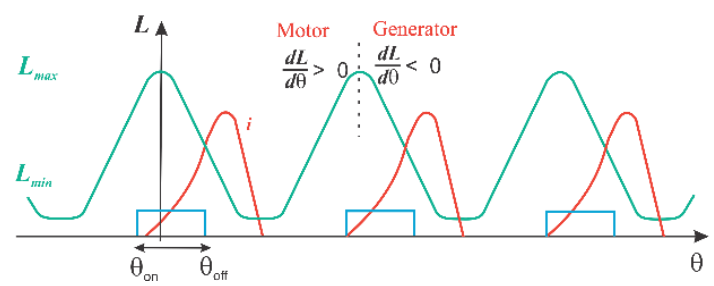

Fig. 2. Typical waveforms of inductance, phase current of an SRG.

\section{Mathematical Modeling}

The mathematical model used to represent the SRM is formed by a set of electrical and mechanical equations according to the block diagram of Figure 3 [3]. It is assumed that the phases are magnetically independent and the flux linkage is considered a state variable.

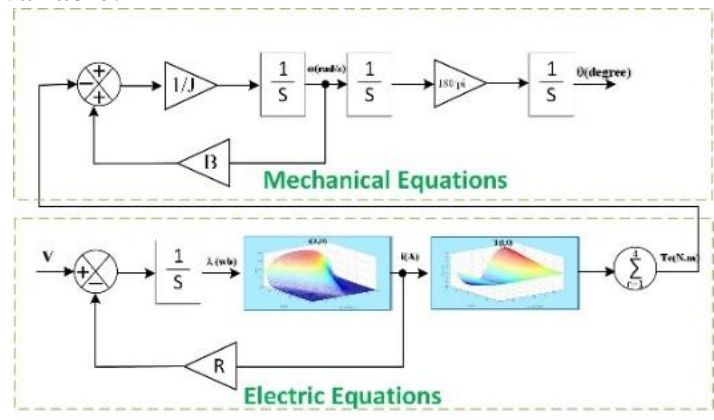

Fig. 3. Block diagram illustrating SRM's set of electrical and mechanical equations.

The linkage flux is obtained from the numerical integration of the difference between the input voltage and the voltage drop across the stator resistance $R_{S}[3][4][7]$.

$$
\lambda_{S}(t)=\int_{0}^{t}\left(V_{S}-R_{S} i_{S}\right) d t
$$

Where: $\lambda_{S}, V, R_{S}$ e $i_{S}$ are the linkage flux, voltage, resistance and stator current.

It is also emphasized that in the machines mathematical modeling the mutual coupling was neglected. Therefore the inductances are considered independently.

The stator current is obtained by a non-linear curve $i(\lambda, \theta)$ as shown in Figure 4. This curve was acquired by the Finite Element Method [3][4]. The electromagnetic torque is calculated by the sum of the contributions of each of the phases.

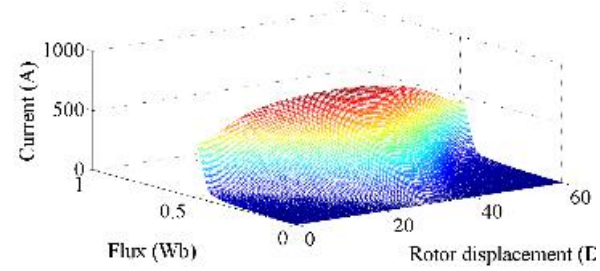

Fig. 4. 3D Current Waveform $i(\lambda, \theta)$.

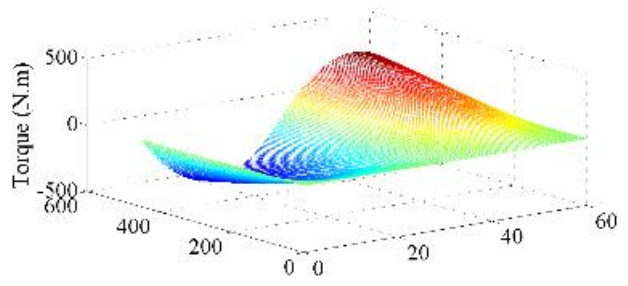

Fig. 5. 3D Torque Waveform $T(i, \theta)$.

Due to the nonlinear characteristics of the flux, the developed torque can be represented by a 
nonlinear curve which is a function of the stator current and the rotor position.

The curve representing the torque $\mathrm{T}(\mathrm{i}, \theta)$ is presented in Figure 5. The electromagnetic torque per phase is mathematically formed by the partial derivative of the co-energy:

$$
T(i, \theta)=\frac{\delta W^{\prime}(i, \theta)}{\delta \theta}
$$

Where co-energy is given by

$$
W^{\prime}(i, \theta)=\int_{0}^{i} \lambda(i, \theta) d i
$$

Through the magnetic characteristics of the SRM the electromagnetic torque can be numerically calculated. The motor dynamic equations as well as the load torque are represented by the expression:

$$
T_{m}=-T_{e}+B \omega+J \frac{d \omega}{d t}
$$

Where $\omega$ is the machine speed $(\mathrm{rad} / \mathrm{s}), B$ is the viscous friction coefficient, $J$ is the inertia, $T_{m}$ is the mechanical torque and $T_{m}$ is the electromagnetic torque.

For calculating the excitation power, load power, mechanical power, generated power and overall system efficiency the equations (5) to (10) were used [3][4][9].

$$
\begin{gathered}
P_{e x c}=V_{e x c} i_{e x c} \\
P_{L}=V_{L} i_{L} \\
P_{m e c}=T_{m} w \\
P_{\text {Loss }}=\left(P_{m e c}+P_{e x c}\right)-P_{L} \\
P_{\text {gen }}=P_{\text {mec }}-P_{\text {Loss }} \\
\eta_{\text {global }}=\frac{P_{L}}{\left(P_{\text {mec }}+P_{\text {exc }}\right)}
\end{gathered}
$$

Where $P_{\text {exc }}$ is the excitation power, $V_{\text {exc }}$ and $i_{\text {exc }}$ are the excitation voltage and current, $P_{L}, V_{L}$ and $i_{L}$ are the power, voltage and current of the load, $P_{m e c}, T_{m}$ and $\omega$ are the mechanical power, generator torque and mechanical speed, $P_{\text {Loss }}$ are the losses; $P_{\text {gen }}$ is the generated power and $\eta_{\text {global }}$ is the overall efficiency.

\section{Open and Closed Loop Operation}

The open-loop operation (without DC bus voltage control) is made with both $\theta_{\text {on }}$ and $\theta_{\text {off }}$ fixed. For closed-loop operation with generated voltage control a strategy was developed that allows the variation of the period width of phases magnetization keeping $\theta_{\text {on }}$ fixed and changing the value of $\theta_{\text {off }}$ (the switches opening angles) through a PI controller.

The controller acting is done only in the converter upper switches. The lower switch is kept in conduction until $40^{\circ}(6 / 4)$ or $26^{\circ}(8 / 6)$ is completed to allow another free-wheeling step occurs between the magnetization and demagnetization of the phases. Then the inverter lower switch is opened causing the energy stored in the phase coil to be delivered to the load.

It is worth noting that this variation occurs in the same way for the other phases of the machine since the PI controller changes the $\theta_{\text {off }}$ value for all phases. The simulation block diagram is shown in Figure 6.

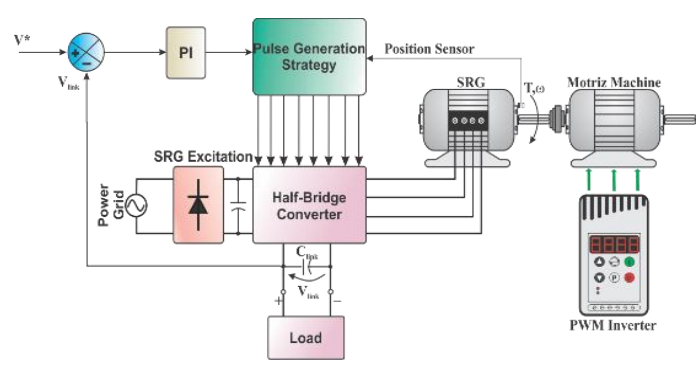

Fig. 6. Block diagram of the system.

\section{Simulation Results}

In the simulation two SRMs acting as generators were used and both with $60 \mathrm{~kW}$ of power. One of them is a three-phase machine (6/4) and the other a four phase machine (8/6). Figure 7 show the complete system simulated.

Initially the SRMs were simulated in open loop. At this stage, the firing angle was gradually altered, allowing the $\theta_{\text {off }}$ angle to be adjusted to guarantee lower losses and better performance.

To adjust the $\theta_{\text {off }}$ angle of the converter lower switches, a set of tests was performed with the machine operating in open loop (without any control). In these tests the angle has varied from 30 up to 44 degrees for the $6 / 4$ machine and from 15 up to 29 degrees for the $8 / 6$ machine. In these tests the mechanical shaft speed was kept constant at 3000 $\mathrm{rpm}$ and the mechanical torque was $191 \mathrm{Nm}$ allowing an operation with $60 \mathrm{~kW}$ of power.

\subsection{Analysis of SRG's under $\theta_{\text {off }}$ Angle Variation}

Figures 8 and 10 show the loss and efficiency curves for $8 / 6$ and $6 / 4$ SRGs. The graphs show that as the conduction angle increases (up to 38 degrees) the losses decrease allowing a gradual increase in generation efficiency. 


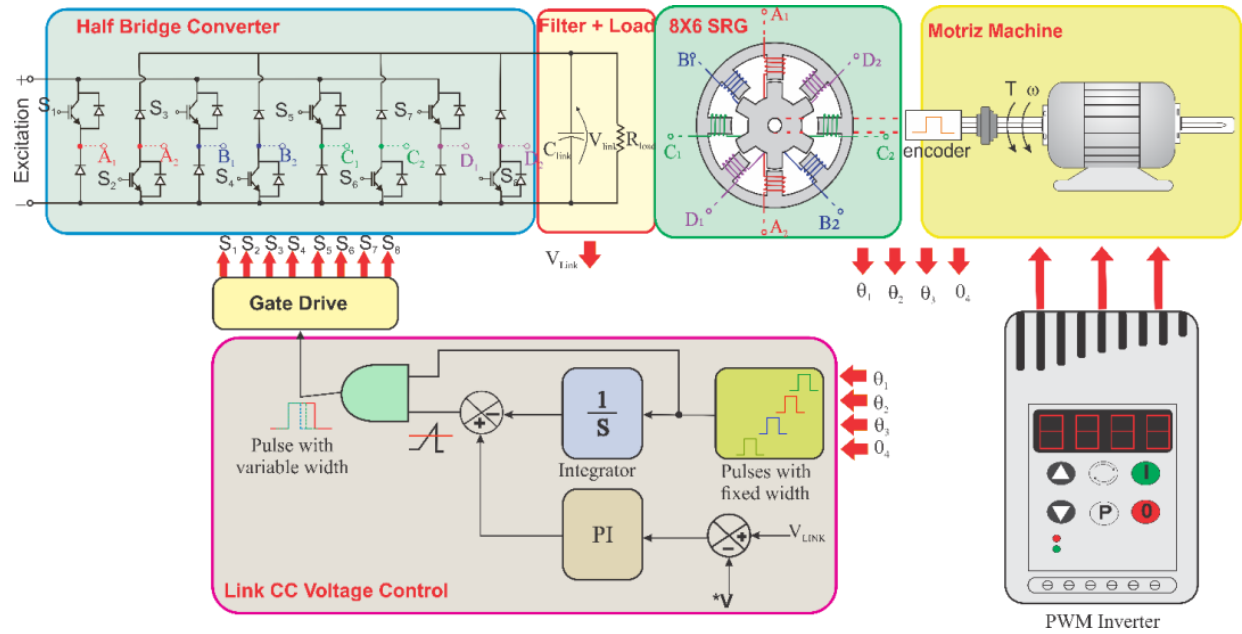

Fig. 7. Complete System: SRG, half-bridge converter, DC link voltage control circuit, PWM drive, load and inverter

For conduction angles above 38 degrees the losses increase and the efficiency decreases slightly. This test enabled the adjustment of the lower switches conduction angle for the SRG $6 / 4$ by 40 degrees. At this time the efficiency is $88 \%$ and the generation losses are $21.75 \mathrm{~kW}$.

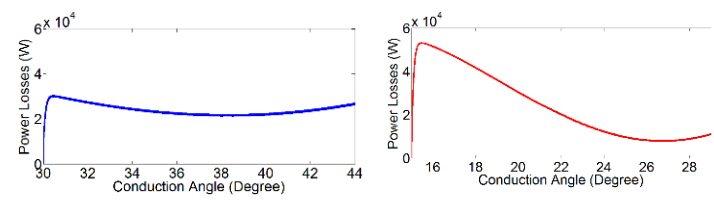

Fig. 8. Losses x $\theta_{\text {off }}$ (a) 6/4 (b) $8 / 6$

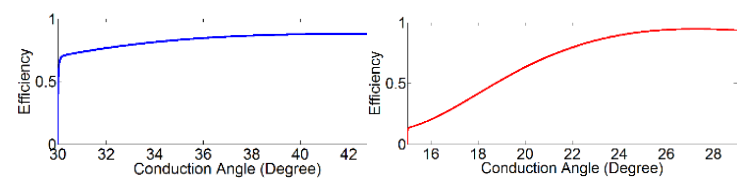

Fig. 9. Efficiency x $\theta_{\text {off }}$ (a) $6 / 4$ (b) $8 / 6$

It is observed that the conduction angle that has better performance is the $26^{\circ}(8 / 6)$ and $40^{\circ}(6 / 4)$. In this period for SRG $8 / 6$ the efficiency reaches $94 \%$ and the losses are only $7.82 \mathrm{~kW}$.

Figures 8 and 9 also show that the $8 / 6$ machine features smaller losses and higher efficiency compared to $6 / 4$ machines.

It is perceived that for SRG 6/4, the operation with $30^{\circ}$ conduction angles show losses of approximately $30 \mathrm{~kW}$ and efficiency near $70 \%$.

In the $8 / 6$ machine the results with $15^{\circ}$ angles are not satisfactory either. In this stage the losses are greater than $50 \mathrm{~kW}$ and the efficiency is slightly larger than $10 \%$.

As the conduction angle increases the losses become smaller on both machines and at the same time the efficiency of the two SRGs significantly improves.

\subsection{Analysis of the SRG's under variations speed}

Figures 10 and 11 show the results for the generated power, efficiency, losses and generated voltage, when varying the machine speed from 1800 rpm up to $12000 \mathrm{rpm}$.

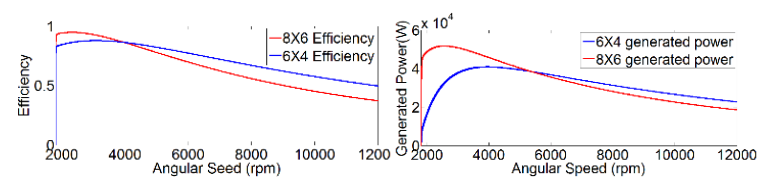

Fig. 10. Efficiency x Speed (a) - (b) Power x Speed

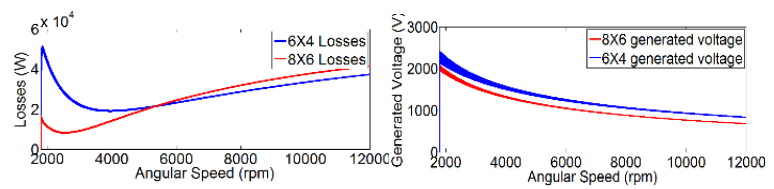

Fig. 11. Losses x Speed (a) - (b) Voltage Generated x Speed

It is noticed that operations with speeds greater than $3000 \mathrm{rpm}$ cause a small decrease in the generated power (Figure 10a) and in the efficiency (Figure 10b) in both 6/4 machine and 8/6 machine.

Figures 11a and $11 \mathrm{~b}$ show that operation at speeds higher than $3000 \mathrm{rpm}$ increase losses and decrease the generated voltage. 
The analysis of Figures 10 and 11 also exhibits that $8 / 6$ machine delivers better results, mainly in operation at the speed of $3000 \mathrm{rpm}$.

It is observed that this machine generates a higher power has higher efficiency and lower losses. However only the generated voltage is smaller for $8 / 6$ machine compared to $6 / 4$ machine.

\subsection{Link Control.}

For adjusting the DC link voltage the SRG speed was maintained constant at $3000 \mathrm{rpm}$. The mechanical torque was retained at $191 \mathrm{Nm}$ sustaining the nominal power of the SRGs in $60 \mathrm{~kW}$.

In the applied strategy a continuous voltage source of $280 \mathrm{~V}$ was employed for SRG excitation.

Figures 12, 13 and 14 show the results of phase voltages, DC link voltage and generator torque respectively for $6 / 4$ and $8 / 6$ SRGs.

The DC link voltage was controlled at approximately $1100 \mathrm{~V}$. It is observed that the DC link voltage (Figures 13a and 14b) for 8/6 SRG presents smaller oscillations when compared to 6/4 SRG. This aspect reflects on the possibility of using a lower value filter capacitor. The 8/6 SRG torque (Figure 14b) also features minor oscillations when compared to that from 6/4 SRG (Figure 14a).

Figure 15 shows the phase current (in red), inductance (magenta) and upper (black) and lower (green) pulse switch for one of the machine phases. It is important to note that the current value for the SRG $8 / 6$ is slightly lower than that shown in the SRG 6/4. It is further noted that the pulse width of the upper and lower switches are different since the cyclic ratio of the upper switch pulse is set to maintain the voltage DC link voltage at the predetermined value.
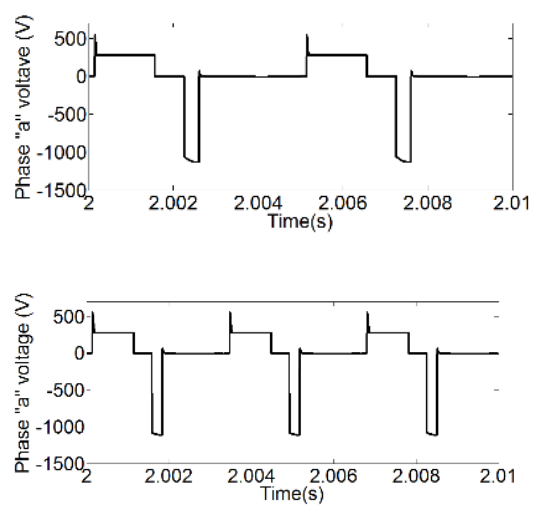

Fig. 12. Phase A Voltage (a) SRG $6 \times 4$ (b) $8 \times 6$
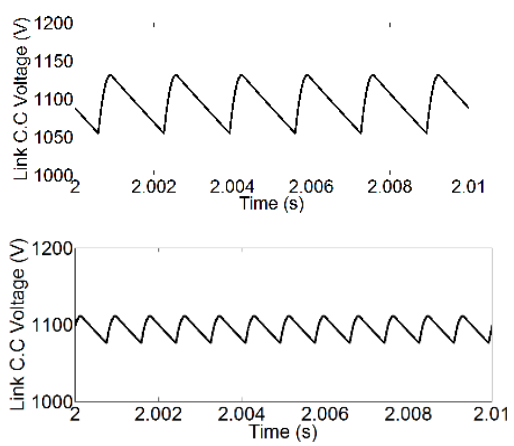

Fig. 13. DC Link Voltage (a) SRG $6 \times 4$ (b) $8 \times 6$
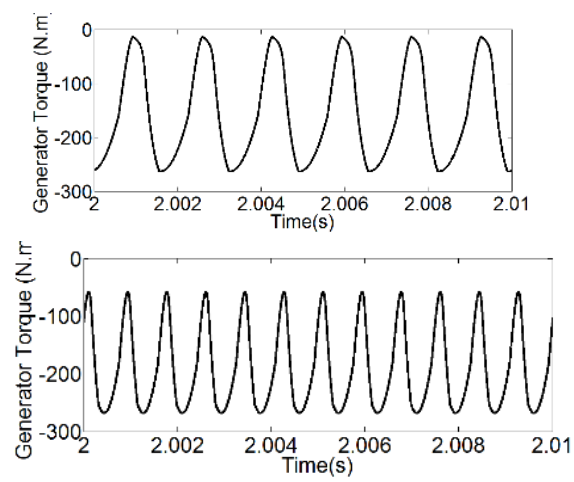

Fig. 14. Electromagnetic torque (a) SRG $6 \times 4$ (b) $8 \times 6$

The results concerning the efficiency, losses, excitation power and power generated for the $6 / 4$ and 8/6 SRG's are shown in Figures 16 and 17 respectively. It can be seen in figure 16a that the efficiency for SRG $8 / 6$ reaches $80 \%$ and for $6 / 4$ is $66 \%$. The losses are illustrated in Figure 16b. In the SRG $8 / 6$ the losses are lower than $6 / 4$ (20.4 and 12.3 $\mathrm{kW}$ ). Additionally, it is noted that the SRG $8 / 6$ requires less excitation power compared to $6 / 4$, as shown in Figure 17a. Figure 17b shows still higher power values generated by SRG $8 / 6(47.7 \mathrm{~kW})$ compared to $6 / 4(39.7 \mathrm{~kW})$.
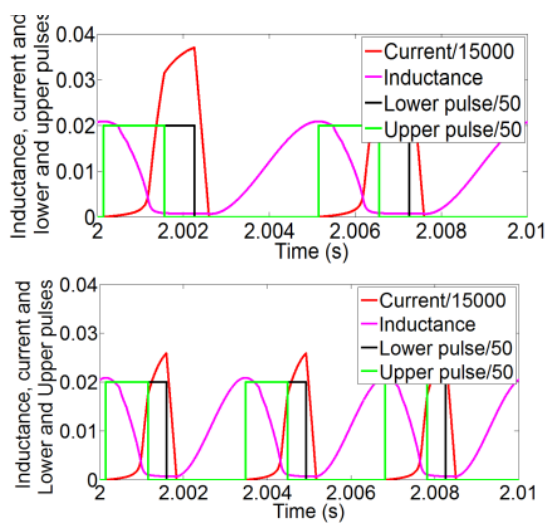

Fig. 15 - Current, Gate pulses e Inductance (a) SRG 6/4 (b) SRG $8 / 6$ 

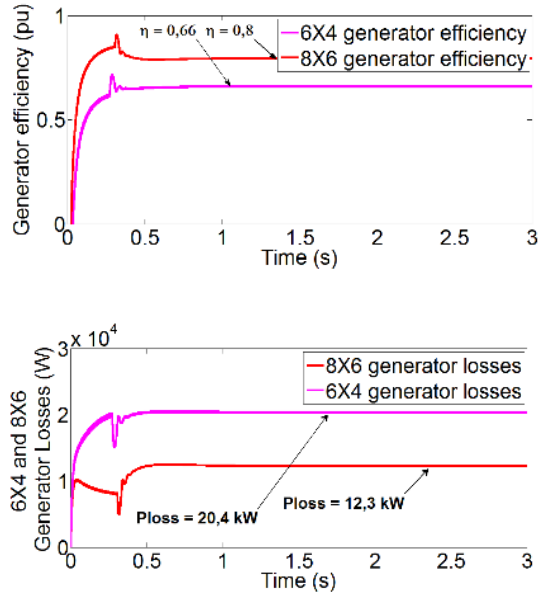

Fig.16. SRG 6/4 and 8/6 (a) Efficiency (b) Losses
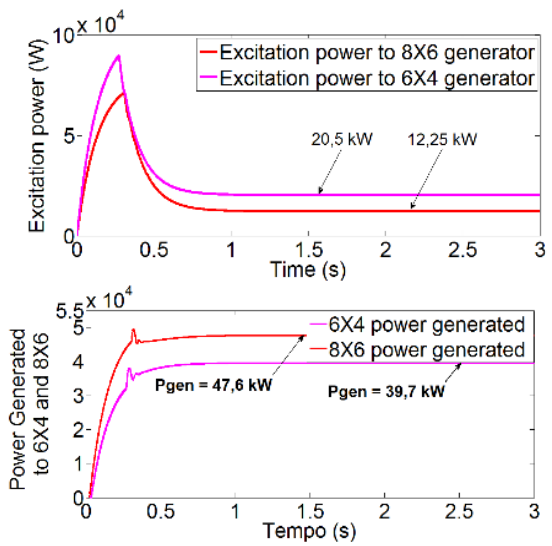

Fig. 17. SRG 6/4 and 8/6 (a) Excitation Power (b) Generated Power

\section{Conclusion}

This work presented a comparative study between two $60 \mathrm{~kW}$ Switched Reluctance Generators, one of them is a three-phase machine with $6 / 4$ poles configuration and the other a fourphase machine with $8 / 6$ poles configuration. The mathematical model presented has included the effects of magnetic saturation. The system modeling has specified the flux as state variable and was based on the stator current curve $i(\lambda, \theta)$ and torque curve $T(i, \theta)$. The curves of efficiency, losses, generated power and generated voltage as a function of the magnetization angles $\theta_{\text {on }}$ and $\theta_{\text {off }}$ were shown for fixed and variable speed. A DC link voltage control scheme was also presented. From the results it was verified that under the same operating conditions the 8/6 SRG presents higher efficiency and generated power, lower losses and a small requirement of excitation power in relation to 6/4 SRG. In addition, it was verified that the $8 / 6 \mathrm{SRG}$ presents smaller oscillations of torque and minor oscillations in the DC bus voltage.

\section{Acknowledgement}

The authors would like to thank IFG for the financial support.

\section{References}

[1] Y.Chang, C.M. Liaw, "On the design of power circuit and control scheme for switched reluctance generator", Transactions on Power Electronics, vol. 23, no. 1, 2008.

[2] Y.C. Chang, C.M. Liaw. "Establishment of a Switched-Reluctance Generator-Based Common DC Microgrid System", IEEE Transactions on Power Electronics, Vol. 26, No. 9, pp. 2512-2527, September 2011.

[3] D. A. Andrade, R. Krishnan, "Characterization of Switched Reluctance Machines Using Fourier Series Approach", in Proc. 36th IEEE Ind. Appl. Annu. Meeting, pp. 48-54, Sep. 2001.

[4] G.P.Viajante, et all, "Estratégia para Melhoria da Eficiência da Conversão Eletromecânica de Energia do SRG", IEEE Eletrônica de Potência, v. 16, N²4, p. 367-375, 2011.

[5] Bao, Y.J.; Cheng, K.W.E. "Research on a novel switched reluctance generator for wind power generation" IEEE PESA, 2011.

[6] Sozer ,Y. and Torrey, D. A. "Closed Loop Control of Excitation Parameters for High Speed SwitchedReluctance Generators", IEEE Transactions On Power Electronics, Vol. 19, No. 2, March 2004.

[7] Silveira, A. W. F. V., Andrade, D. A., Fleury, A., Gomes, L. C. Bissochi C. A., de Paula, H. "Generated Voltage Control In A Switched Reluctance Motor/Generator" Eletrônica de Potência, v. 15, n. 3, p. 203-212, jun./ago. 2010.

[8] Chen, H., Jason J. G, "Implementation of the ThreePhase Switched Reluctance Machine System for Motors and Generators" IEEE Transactions On Mechatronics, Vol. 15, No. 3, June 2010.

[9] Fleury, A. V. S., Silva F. S., Araújo, W. R. H., Andrade ,D.A., Silveira ,A. W. F. V. "Reduced switch count converter for switched reluctance generators" Eletrônica de Potência, Vol. 13, no. 3, Agosto 2008. 